\title{
Moral Education in the Modern University
}

\section{Paper prepared for the Autumn General Meeting The American Philosophical Society}

\author{
November 8, 1996 \\ Nannerl O. Keohane \\ Duke University
}

Colleges and universities assert that we are engaged in educating leaders for our nation and the world. We send our graduates forth with stirring rhetoric about how their education has prepared them to repair all the messes of the past. We argue that a good education requires learning from people with many kinds of backgrounds, and that our responsibilities include training people from all walks of life. Thus we seek students and faculty members of different races, religions, geographies, economic and ethnic groups, and confidently proclaim the advantages of diversity.

On both these fronts, our rhetoric is better than our performance. The educational experience of many students gives little evidence of preparation for leadership in a democracy. And critics point out that patterns of selfsegregation are common in our diverse student bodies, so that the putative advantages of learning from those unlike oneself remain largely theoretical. Nonetheless, I shall argue, our campuses are well-placed to take advantage of the educational benefits of diversity, bridge the cultural divides that undermine our political system, and prepare leaders from all parts of society, if we have the will to do so.

Colleges and universities have a major influence on the development of the character of our students through the varied activities of their college years. The large majority of undergraduate students in many institutions are between late adolescence and early adulthood. Experiences on campus for these students are often exceptionally intense and formative. These experiences shape the character of students every day in minute ways, with too little attention, on the part of the students themselves, or their teachers and counselors, to exactly what sort of character is being formed. Educational leaders -- faculty as well as administrators -- should give more thought to how we might contribute to the development of graduates prepared to grapple with the daunting problems of the societies of the future.

\section{Universities as Schools for Ethical Understanding}

During the first years of the republic's history, colleges and universities accepted as one of their basic responsibilities the education of citizens and leaders in a democracy, as they trained teachers for the schoolrooms and ministers for the church. This responsibility was clearly understood: "to train the Christian citizen," through study in the classics, mathematics, rhetoric and ethics.

By the end of the last century, this definition ceased to be pertinent for many of our colleges and universities; it came to be seen both as too narrow and as too particular. The definition was questioned long before the 1960s, despite the claims of critics who trace all our educational ills to that tumultuous decade. One of the most significant texts in that re-definition was the report of the Harvard Committee on the Objectives of a General Education in a Free Society, charged by President James Bryant Conant -- usually known simply as the "Red 
Book." The second chapter of that report sketched out a new definition of general education appropriate to the contemporary world, one that would balance the "necessity for common belief with the equally obvious necessity for new and independent insights leading to change."

In addition to seeking a balance between tradition and innovation, the Harvard report also sought to define an education that would work both for the "good man" and the "good citizen," balancing free enquiry and critical individualism with the necessity for individuals to "subordinate their individual good to the common good."

In recent years, a great deal of attention has been paid in this country to resolving the first dilemma posed by the Red Book: combining due attention to the historic canon, the "classics," with appropriate opportunity for learning about burgeoning new fields of knowledge across the curriculum. This tension is memorialized in the "canon wars" and the endless debates over "political correctness."

I would argue, however, that the second dilemma identified by the Harvard Committee -- to educate freethinking individuals who will also be good citizens, contributing members and leaders of society -- is an even more significant challenge for educational leaders today. Just as it has become unfashionable to teach civics courses in high school, so the faculties and leaders of higher education have been largely silent about any obligations to mold citizens. There are many reasons for this reticence; but it is increasingly unfortunate and even dangerous, in light of the pressing need for education in civic virtue in a society that is increasingly, and dangerously, fragmented.

Political philosophers, past and present, have identified a number of aspects of civic virtue. For our purposes, I shall define this term as including several components: a) an understanding of the interconnectedness of human beings, in the sense of our dependence on others to provide many of the goods and services, both tangible and intangible, that make life worth living; b) an appreciation of the need to subordinate some of our selfish impulses to the needs and aspirations of others in order to create a more secure and fruitful society in which to live; c) a measure of tolerance for individuals whose ways of doing things are different from one's own; and d) a readiness to collaborate with others in order to achieve desirable goals that no single individual can successfully pursue.

These are simple principles, but they have substantial implications for ethical behavior. They are more procedural than substantive.

They do not require specific agreement on the goods to be sought through collaboration, nor even a prior commitment to values such as liberty or equal opportunity that may in other contexts be thought essential to civic virtue. The principles are primarily prudential, but they spring from an enlightened prudence that recognizes that individual needs and desires are most likely to be satisfied through some measure of reciprocity.

Such rudiments of civic virtue are most easily learned in the family and extended to the larger world. In a family, a small town or other comparatively homogeneous setting, human interactions are not complicated by profound differences in perspective about what collaborative goods are worth pursuing, or by cultural differences so great as to make communication about shared purposes a daunting task. Even in families, there are differences and tensions that make tolerance and collaboration difficult. Such differences are multiplied many-fold in the larger society where civic virtue could provide an ordering framework for our lives.

We can no longer assume that citizens grow up in settings where such principles are routinely taught or practiced. Nor can we assume that all citizens will be exposed to such basic principles of morality through religious training, or in their early schooling. As a result, many people in contemporary society are ill-prepared to function as productive members of a complex community, much less to take advantage of community to achieve any larger purposes. 
Among contemporary institutions, colleges and universities are uniquely well-placed to train young people in the rudiments of civic virtue, as I have just defined it. Campuses are concentrated human communities, small enough to be encompassed through a single organization, large enough to present many of the challenges and opportunities that arise in the larger world. Students live closely together, sharing aspects of their lives in an intimacy they will not elsewhere experience outside the family. Such communities offer daily practical experience in the consequences of ethical and unethical behavior.

It is easy to grasp the principle of self-interest rightly understood in a dormitory setting. Accommodation to different sleeping habits between those who are accustomed to being in bed by eleven o'clock and roommates who like to study to the accompaniment of loud stereo music till three a.m. requires learning how to compromise, working through differences, perhaps with the aid of an older student who serves as a resident advisor. Honor codes, athletic teams, student judicial councils enforcing rules the students themselves have helped devise -- these are excellent places to learn the habits of trust and collaboration that provide the basis of ethical behavior in a complex society.

Universities also provide multiple opportunities for deliberately reaching out past one's own selfish horizons to help those in need. Community service projects are a major feature of life on many campuses these days, through fraternities or sororities, church groups, special interest clubs or residence halls. Students may be cynical or apathetic about the political system; but they are quick to respond to the needs of children whose lives and futures are at risk, to the impoverishment of people in soup kitchens. The traditional idealism of young people finds its most common contemporary expression in such community service programs.

Too seldom, however, do we provide opportunities for students to reflect carefully on any of these experiences. We cannot just take for granted that students will draw the morals from such actions on their own. We should, more often than we do, focus their deliberate attention on the lessons to be learned.

\section{Obstacles to moral education}

The most significant obstacles to civic education on campus today are in our own practices and expectations. Faculty and staff members, to whom students look as sources of authority and also as role models, are for a variety of reasons hesitant to confront moral dilemmas head-on, or to engage in what might seem to be a form of preaching or social engineering.

Faculty members in every discipline are trained to impart the knowledge particular to their discipline. Staff members in student affairs offices are trained to be sensitive to different situations and to provide supportive, nurturing counseling to each individual student. Neither faculty nor staff members generally think of themselves, nor do they wish to become, personal sources of moral authority or insight. Like many parents today, they are hesitant to see or present themselves as models of behavior, and are suspicious of any terrain where they might be expected to offer insights into moral dilemmas. At a time when even parents are reluctant to stand in loco parentis, it is hardly surprising that faculty and staff hesitate to do so.

It is true that genuine engagement with teaching on the part of faculty members tends to lead to engagement with students as well, to an interest in how they are doing individually, to concern about what they are learning and what sorts of persons they are becoming. Even if faculty members do not think of themselves as "moral educators," those who take their teaching seriously are likely to pose questions and encourage reflection about the larger implications of whatever it is that they are teaching.

Professors nowadays, however, face multiple demands and pressures on their time. Many are strongly 
motivated by disciplinary loyalties and professional relationships with colleagues around the world. Sustained, direct engagement with individual students is not at the heart of our current system of academic incentives and rewards. Addressing this complex matter of incentives in the university is not easy; doing so, however, promises multiple rewards, including a greater likelihood of thoughtful attention to the developing character of one's students. Fortunately, on many campuses, the place of teaching in the incentive structure for professors is being re-examined. This trend, in itself, is likely to lead to more consideration of the opportunities faculty members have to help students develop their character during their college years, rather than simply mastering a prescribed body of material.

Faculty members also are trained to understand the importance of objectivity, of presenting a broad range of views on any subject, so that students can form their own opinions on the basis of all the relevant information. This principle of objectivity is crucial in education as we define it on our campuses, even though most professors recognize that they can never be entirely neutral or Olympian. The most thoughtful explicate their own biases or perspectives when these are relevant -- not so that students will feel obligated to adopt these perspectives, but so they will think about the implications of these perspectives as students make their own judgments about what they are being taught.

It is important that professors not abuse the authority of the classroom by trying to instill or enforce a particular narrow viewpoint on any subject. It does not follow, however, that all subjects involving subjective judgment or opinion are off limits for the classroom. The principle of objectivity is sometimes invoked to avoid moral topics and arguments entirely, on the grounds that it is impossible to be objective about such things, that breaching David Hume's impenetrable barrier between fact and value inevitably involves some form of intellectual intimidation. In fact, there are well-understood ways of approaching difficult moral dilemmas, and intellectually honorable ways of exploring them together.

Such explorations may involve deliberate attention to the dynamics of the classroom, conceiving it as a kind of public space where students should think about difficult issues of communication and listening, being sensitive to the points of views expressed by others. Or they may involve the willingness to preface abstract discussions in the biology classroom with attention to some major contemporary debate about the allocation of scarce medical resources. An anthropologist or psychologist might reflect on the tensions occasionally encountered in studying fellow human beings, including the potential effects of one's study on one's subjects and their lives.

Faculty members in several disciplines are specialists in the core materials of ethics, primarily in philosophy and religion, but also in psychology, classics, history, literature. These professors are knowledgeable about the rich corpus from which ethical truths are distilled and shared -- great plays or novels or scriptural texts or works of moral philosophy, crucial heroic or shameful moments in the lives of nations or individuals.

We should encourage professors in all these parts of the university to discuss moral issues straightforwardly in their classes, not in order to persuade their students to adopt a particular brand of ethical philosophy or convert them to a specific religion, but to encourage students to think carefully about ethical dilemmas, and provide them with more broadly-based and supple frameworks for doing so.

Similarly, staff members in student affairs are trained to recognize and combat unhealthy behavior. They follow certain basic principles in offering advice or support to every student, even as they tailor their advice to individual situations. Such counselors should be encouraged to be more explicit about the principles they are following, and about the importance of behaviors that conduce to a more civil community on campus.

These are not easy conversations, but they are important in the formation of character. If colleges and universities do not provide occasions for such conversations, many young people will never engage in them at all. 


\section{The uses of diversity}

One of the major contemporary challenges to civic virtue is society's great complexity -- not just its formidable size and scale, but the large number of different cultures, languages, religions, racial and ethnic groups that compose the United States of America. Members of these different groupings may form small subcommunities that provide traditional support for one another. But it is rare for citizens to reach across the barriers that separate these subcommunities to develop ethical identification with each other.

The campus is one of the few places in America today where people have easy opportunities to learn from one another both the ethical practices of different cultures, and the imperative importance of living more humanely together and caring for one another. Colleges and universities are among the most diverse institutions in our society, in which people of many different cultures and backgrounds come together for four years of intense and concentrated experience.

The difficulty, of course, is that rich opportunities for education from diversity remain unexploited. Too many students spend their years on diverse campuses ensconced in homogeneous subcultures, with only the most superficial contacts with peers who are unlike themselves. Furthermore, the fact of diversity in the classroom and elsewhere on campus can become an obstacle to the use of it, if faculty and staff members are overly timid about exploring it, or take it as an excuse to avoid unpleasant topics.

At the same time that our institutions of higher education have become more diverse, the willingness to tackle issues raised by diversity appears to have eroded among faculty, students and staff members. We are often reluctant to pose questions about diversity for fear of offending a member of another subculture. The pride in cultural identity engendered by a critical mass of students from any particular subculture can itself become an obstacle to cross-cultural understanding. Such difficulties are not unique to our campuses; they are endemic in the world outside our borders. Here again, I would argue, colleges and universities have a particular obligation, and opportunity, to try to transcend such barriers.

In contemporary American society, and surely on our campuses, many of the most visible and apparently stubborn barriers have to do with race. Beliefs about how people of different races should interact with one another, on campus as elsewhere, range across a broad spectrum. Harvard Law Professor Randall Kennedy describes four kinds of "racial integration," ranging from "amalgamation" to what he called "pluralist integration." Amalgamation is integration by "the literal blending of races" through intermarriage, to create "a new, distinctly American multiracial hybrid." Next along this spectrum he places "the brand of integration associated with Martin Luther King, Jr.," which neither explicitly promotes nor discourages physical union, but "champions the creation of new communal affiliations in which interracial affections are a positive good." Then comes "diversity integration," which he calls "the most widely practiced and consequential form of racial integration" today. This form concentrates less on interracial attachments and more on power, on the "strategic placement of blacks" in influential forums, in a wide variety of institutions from workplaces to boards of directors. Finally, there is pluralist integration, which resists racial blending or mixing "as diversions from the more urgent project of inculcating a strong sense of racial kinship among colored people."

In the pluralist model (to which some might deny the label "integration"), the assumption is made that group competition is a fact of American life, that racial inequality will be a permanent feature of our landscape, and that the only workable and desirable form of "integration" is a better power balance among groups so that previously disadvantaged groups can engage in more effective bargaining. Proponents of this view want to "participate in, contribute to, and benefit from the American polity," rather than withdrawing entirely into a separate state or economy, but they do not wish to lose their traits of group identity or solidarity in doing so. 
Pluralistic integration aims for the effective integration of groups rather than individuals.

On our campuses these days, all four of these types of integration find adherents. In practice, the leaders of higher education generally strive for a combination of the second and the third -- increasing power for members of minority groups, yet also fostering interracial and inter-ethnic friendships and communal affiliations. On campus as in the larger society, however, some of the most effective leaders of minority groups are proponents of "pluralistic integration." They press for separate housing and support, clubs and cultural centers. They encourage students to devote their time and energies to understanding and working for their own people, in social organizations, courses on African-American (or, for other groups, Asian-American or HispanicAmerican) history and culture, so that the university years can be used to prepare graduates for leadership in a world where pluralistic integration is either the best that can be hoped for, or the preferred good for which one should strive.

It is important to understand the paths of both logic and emotion that lead some students and faculty members to think along these lines. There must be spaces and times where minority students can support one another and develop a better understanding of, and pride in, the heritage of African-American or other cultures. However, just as the unexamined assumptions brought by white students from suburbia to the university must be unsettled, it is important to unsettle the assumption that pluralistic integration is the only way to go.

We should endeavor to construct a community on campus in which all participants experience others in a more than superficial fashion. Constructing such a community involves deliberately fostering learning experiences that lead to a greater understanding of diversity -- through the curriculum, the provision of extracurricular programs and symposia, the design of structures and patterns of residential life, support for student groups that aim for this result, as well as admissions and faculty recruitment practices. An education worthy of the name involves overturning established expectations and opening doors to different worlds. Such an approach also is most likely to produce graduates who are well-prepared to lead in a multifaceted society, empowered by a truer understanding of the potential opportunities of such a society.

James A. Joseph has recently published a book called Remaking America: How the Benevolent Traditions of Many Cultures are Transforming our National Life. The book is an impressive compendium of the varieties of voluntary activity which are part of the traditions of several different peoples -- African Americans, Asian Americans, Latinos and Native Americans. Each has distinctive lessons to teach about ethical behavior and time-tested practices of mutual support.

This is a good example of the uses of diversity in education. As human beings, we are universally in need of the support and comfort of others in times of adversity. There are many different ways of providing that support, and in learning about those ways, we come to understand more about the way other people live. We also have the opportunity to adapt "our own" culture by acquiring new ways of meeting fundamental needs, developed by other cultures.

Our diversity should become a point of healthful tension rather than hostile suspicion or simplistic celebration. In classical dialectical fashion, the thesis of "one's own" societal culture should be set against the antithesis of the beliefs and practices of other people. The resulting synthesis for which moral education should aim is not an undifferentiated homogeneous mass, but a refined, informed and tempered dedication to "one's own" principles -- refined by a clearer understanding of the sources and implications of those principles, informed by an awareness of alternatives, and tempered by some degree of humility in the face of the large number of ways human beings have of moving through the world.

Such a state of mind is well-suited to the practice of civic virtue as I defined it earlier. Civic virtue in this modest sense provides a minimal foundation for acquiring other virtues, for the fuller development of character 
that we hope will be part of the lives of all our students. It does not determine the course of that moral development, and allows for numerous different conceptions of and paths to the good life. But it does provide a sturdy and supple framework for living in, and leading, a pluralist democracy.

\section{Principled Intolerance}

Another of the challenges we face in designing effective civic education is the stubborn fact that some subgroups in our society deny full humanity to members of other groups, whether along racial, religious or gender lines. Such groups profess principles at odds with the basic elements of civic virtue, even in the comparatively "thin" procedural definition used in this discussion. They disallow tolerance for other approaches to the good life and forbid open communication with members of other subgroups.

Criteria for admission to our colleges and universities, which emphasize traits such as curiosity and breadth of experience, as well as the self-selection of those who choose to study on our campuses, exclude the most obdurate members of closed societies. Most campuses are, and are known to be, places where open discussion of all kinds of ideas is encouraged, where principles are challenged and rational examination even of deeply held beliefs is fostered. Members of intolerant subcultures who are intent on continuing the strength of their beliefs in the next generation are unlikely to send their children to our institutions.

However, intolerance and the denial of reciprocity are not confined to hard-core members of closed subcultures. Some students profess a strictly defined conception of the good life and are intent either on compelling others to share it, or protecting it against compromise or dilution in any form. Campuses provide particularly powerful sites for challenging such obduracy, for eroding the sense of closed certainty by exposure to different ways of configuring the world. Equally important, campuses provide excellent opportunities for other students to learn how to recognize and deal with the kind of closed-mindedness that makes deliberation and compromise impossible.

During the past academic year, for example, the legislature of the Duke Student Government was asked to extend recognition, in the form of financial support and legitimacy, to a militantly Christian organization. The leaders of the group -- not themselves members of the student body -- made quite clear their intentions to convert as many students as possible to their particular brand of Christianity. The student government leaders declined to provide support until they could explore allegations that the group was engaging in unacceptable practices. Their findings led them to deny recognition, on the grounds that the record demonstrated psychological harassment and the isolation of students. The DSG leaders were criticized by other students, including the editors of the student newspaper, for discriminating against the group because of its religion. The discussion of this issue on campus provided an excellent opportunity for thoughtful students to reflect on the purposes and limitations of tolerance in an open society.

\section{Conclusion}

In the second volume of Democracy in America, Tocqueville identifies as one of the most marked characteristics of the citizens of the United States what he calls "individualism." This sentiment "disposes each member of the community to sever himself from the mass of his fellows and to draw apart with his family and his friends, so that after he has thus formed a little circle of his own, he willingly leaves society at large to itself." 
Tocqueville worried about this individualistic tendency, which he identified as the characteristic deformation of a democratic people, free and equal, without traditional bonds of hierarchy and privilege. He ascribed the success of the United States largely to our free institutions, designed to draw people into public activities in which private interests are clearly implicated, actions undertaken by local governments and voluntary associations, such as building roads or schools.

Such institutions (along with the free press and the powerful sentiments of religion) form the bonds that are the basis of everyday morality. Tocqueville describes this common sense morality in the language of the Enlightenment principle of "self-interest rightly understood." This principle, he notes, is "not a lofty one, but it is clear and sure." It does not aim at brilliant acts of heroism, but it accomplishes its goals, is within the reach of everyone, and works surely and habitually to draw people out of selfish isolation into behaviors that benefit others as they benefit themselves.

How prescient Tocqueville was in many things, including foreseeing the gradual decay of civic virtue in America. In our large, increasingly complex and multifaceted society, more and more Americans have indeed lost touch with any general associations that bring people together across class and cultural divides. Many have withdrawn to particularistic islands, whether behind the gated walls of a homogeneous housing complex or into the stratified neighborhoods of our cities. Such particular communities, class-based or religious or ethnic, may bring solace and companionship, as compared with the loneliness of the truly isolated individual. But they also tend to separate their members from the larger society, and in doing so, undermine any sense of over-arching common purpose, of a durable society composed of diverse people who share certain basic obligations to each other.

Few parts of American society were ever as tightly knit or virtuous as some of Tocqueville's more idealistic passages would lead us to believe. But he was surely right in his diagnosis of those attitudes and behaviors that bring human beings together in community, and his prognosis about the centrifugal factors that pull us apart in an increasingly complex society. As many thoughtful observers of these tendencies have noted, there is a great need for social regeneration in contemporary American society, the creation or renewal of ties that bind citizens together across boundaries of class, race and region. Without such ties, we are in danger of a fragmentation that renders us incapable of responding effectively to challenges that threaten us internally or externally -- in the economy, the environment, the international arena -- a fragmentation that engenders hostile suspicion or ignorance of others that is a fertile breeding ground for inhumane behavior.

Tocqueville was surely also prescient in warning that we cannot take for granted that Americans always or instinctively will understand the principle of "self-interest rightly understood." He therefore put considerable emphasis on education as a crucial element in preserving American civic virtue.

... I do not think [he wrote] that the system of self-interest as it is professed in America is in all parts selfevident, but it contains a great number of truths so evident that men, if they are only educated, cannot fail to see them. Educate, then, at any rate, for the age of implicit self-sacrifice and instinctive virtues is already flitting far away from us, and the time is fast approaching when freedom, public peace and social order itself will not be able to exist without education.

No one claims that an education designed to mold free-thinking citizens is easy to provide, but there are models for success in doing parts of it on campuses around the country. We need to share information about these successes, and encourage faculty and staff members to take moral education seriously.

We should not underestimate the obstacles to this kind of education, nor overstate our ability to deliver it to all our students. Nor should we assume that our campuses are the only site for such endeavors. The contributions of schools, churches, civic associations, local governments, and many other institutions will be crucial in this 
effort. But we must not use, as an excuse for indifference, either the fact that others share this responsibility, or that colleges and universities have many other missions besides moral education. At this point in the history of this society, that mission is among the most imperative we have.

I am grateful to members of the Society for their thoughtful questions, to colleagues at Duke for good suggestions, and to participants in the symposium on "Common Values, Social Diversity and Cultural Conflict" held at the Center for Advanced Study in the Behavioral Sciences on October 18, 1996, for comments on an earlier draft of this paper.

Comments? Problems? Contact the WebMaster.

Back to the DukeNews Home Page 